\title{
PERANCANGAN GAME UNTUK MURID SEKOLAH DASAR BERGENRE ARCADE DISERTAI MATERI SOAL PELAJARAN DENGAN MODEL ADDIE
}

\author{
Rina Alfah \\ Fakultas Teknologi Informasi, Universitas Islam Kalimantan MAB Banjarmasin \\ Email : rina.alfah.05@gmail.com
}

\begin{abstract}
Abstrak
Game merupakan salah satu media hiburan karena mampu mengurangi tingkat kepenatan murid sekolah dasar dari rutinitas pembelajaran konvensional di sekolah. Perancangannya bergenre arcade dengan jenis Auto runner tetapi tetap memiliki edukasi, yaitu menyisipkan pertanyaanpertanyaan seputar mata pelajaran sekolah dasar untuk menambah nilaillife player/si pemain . Pembuatan game edukatif ini memiliki tujuan agar anak-anak bisa bermain game tapi bukan hanya sekedar bermain saja tapi juga bisa belajar. Dengan adanya game ini menambah referensi hiburan mendidik untuk anak-anak khususnya murid Sekolah Dasar. Perancangan Game ini menggunakan metode Addie (Analysis-Design-Development-Implementation-Evaluation) dan proses pembuatan nya menggunakan Tools Construct2.
\end{abstract}

Keyword : ADDIE, Construct2, Game Arcade, Game Edukatif.

\section{PENDAHULUAN}

Game jika diartikan kebahasa indonesia adalah permainan. Dengan adanya teknologi seperti sekarang ini, game dapat diartikan secara lebih luas lagi. Jadi, secara istilah pengertian game adalah permainan yang sudah diprogram pada satu perangkat yang dapat dijalankan secara offline dan online. Pada jaman sekarang, anak- anak berusia 2 (dua) tahun pun sudah mengenal adanya game mobile, termasuk anak usia pra sekolah bahkan sempai dewasa. Mereka bahkan ada yang kecanduan memainkan game secara terus menerus tanpa mengenal waktu. Dari latar belakang diatas , maka kami melakukan penelitian merancang pembuatan game edukatif khusus nya untuk murid sekolah dasar supaya anak bukan Cuma sekedar bermin game saja tetapi juga ada pelajaran yang dimuat didalam alur game tersebut. maka perlu sebuah inovasi baru dalam aplikasi game tersebut yaitu berupa munculnya soal-soal untuk anak SD agar membuat game tersebut tidak hanya untuk bermain-main saja tetapi mengandung pelajaran yang sesuai untuk anak terutama murid Sekolah Dasar. Untuk Itu kami mengambil judul "Perancangan Game Edukatif Untuk Murid Sekolah Dasar Dengan
Model Addie (Analysis-Design-DevelopmentImplementation-Evaluation) “.

\section{LITERATUR}

Game merupakan sesuatu yang dipergunakan untuk kita bermain atau sesuatu yang dipermainkan secara perorangan maupun kelompok. Untuk Setiap permainan/game terdapat alat dan aturan-aturan/rule, sehingga pemain/player membutuhkan keterampilan strategi, sebuah kesempatan, ataupun sebuah keberuntungan. Game/permainan dapat kita lakukan dengan dimainkan secara multiple player ataupun single player. Game/permainan dengan single player merupakan game/permainan yang memiliki jenis tantangan yang lebih unik, dimana para pemain akan menggunakan keterampilannya sendiri bahkan untuk melawan waktu/kemungkinan lainnya.

Construct 2 merupakan softwere/tools perancang dan pembuat game yaitu merupakan aplikasi berbasis HTML5 yang dikhususkan untuk platform 2D. Softwere/tools ini dikembangkan oleh Scira. Berbeda sekali dengan Adobe Flash CS 6 untuk Construct 2 tidak menggunakan bahasa pemrograman khusus, karena pada semua perintah yang dipergunakan untuk game diatur dengan 
menggunakan Event Sheet dan Action saja. Sehingga untuk mengembangkan alur game atau aplikasi , Construct 2 kita tidak perlu mengerti atau menguasai bahasa pemrograman yang begitu sulit, apalgi orang awam yang tidak belajar pemrograman (Damar, 2016)

Construct2 banyak memiliki keunggulan diantaranya adalah Powerfull Event System. Dengan menggunakan Construct2 orang dapat membuat game atau aplikasi, termasuk untuk media pembelajaran berbasis mobile, dengan lebih mudah dan sederhana. Hal ini dikarenakan orang tidak perlu menggunakan bahasa pemrograman yang begitu rumit sebagaimana softwere pembuat game lainnya. Contruct 2 sudah menyediakan EventSheet yang berisi pernyataan kondisi atau pemicu/sebuah keadaan. Jika kondisi tersebut sudah terpenuhi, tindakan atau fungsi lainnya dapat dilakukan. (Roedavan, 2015)

Keunggulan Constuct2 yang lainnya yaitu Quick and Easy. Construct2 mempunyai antar muka / Ribbon yang cepat/quick dan sangat mudah dipahami. Layout editor nya menyediakan antar muka what you see is what you get untuk mempercepat perancangan isi game. Sehingga, apa pun yang dilihat dalam desain layoutnya adalah tampilan yang kita dapatkan ketika game di run/ dijalankan. Dengan begitu orang dapat menggunakan Construct2 untuk membuat game dan aplikasi lebih mudah dan lebih cepat tentunya. Selain keunggulan-keunggulan tersebut, keunggulan Construct2 lainnya yaitu Multiple Export. Construct2 sudah dapat mempublikasikan game atau aplikasi yang dibuat dengan berbagai pilihan platform tetapi hanya dengan satu project. Game Costruct2 dapat diterbitkan pada platform berbasis web seperti Newgrounds ,Chrome Web Store, Facebook, Firefox Marketplace ,Kongregate. Construct2 juga dapat di ekspor langsung ke desktop PC, Mac atau Linux dengan menggunakan Node Webkit. Selain bisa mempublikasikan ke Windows Store atau sebagai aplikasi Windows Phone . Pengguna dapat dapat pula mengekspor game ke iOS maupun Android dengan menggunakan PhoneGap , appMobi ,CocoonJS. Dengan berbagai dukungan platform yang sangat luas, pengguna dapat memiliki akses yang sangat luas untuk pemain.

Desain yang digunakan dalam
penelitian ini yaitu Model ADDIE ,

adalah salah satu proses pembelajaran dan penelitian yang bersifat interaktif dengan beberapa tahapan dasar pembelajaran yang sangat efektif, begitu dinamis dan sangat efisien. Model ADDIE (Analysis Design Development Implementation Evaluations) sebenarnya berawal dari konsep sebuah Model Desain Instruksional serta Teori untuk Angkatan Darat AS pada tahun 1950. Kemudian pada tahun 1975 kemudian dikembangkan lagi oleh FloridaState University yang digunakan pada semua Angkatan Bersenjata AS.

Beberapa Praktisi pendidikan membuat beberapa revisi dan kemudian di pertengahan 1980-an maka muncullah sebuah model yang lebih interaktif dan dinamis dari aslinya/versi sebelumnya. Model ini kemudian dapat juga digunakan untuk berbagai macam bentuk pengembangan produk-produk seperti strategi serta metode pembelajaran, yaitumedia dan bahan ajar (Alfah, 2016). Model ADDIE bisa menjadi pedoman dalam membangun perangkat serta infrastruktur sebuah program pelatihan atau pembelajaran yang sangat efektif, dinamis dan mendukung kinerja pelatihan nya sendiri dengan beberapa tahapan yang dilakukan. Jadi kami mencoba menerapkan Model Addie untuk mendasari penelitian perancangan game edukatif yang sudah kami buat menggunakan Construct2 tersebut.

\section{HIPOTESIS}

Anak-anak SD pada saat ini banyak yang hanya bermain menggunakan Smartphone untuk bermain tanpa belajar dan anak-anak hanya mengetahui game yang sedang trending seperti seperti PUBG, Mobile Legend, AOV, dan lain-lain. Padahal game tersebut jelas untuk anak remaja atau orang dewasa. Banyak anakanak SD(Sekolah Dasar) yang tidak ingat belajar karena keseringan game tersebut. Dari permasalahan di atas maka kami merancang dan membuat game edukatif bergenre Arcade yang diharapkan bisa membuat anak-anak bermain sambil belajar dengan adanya perancangan dan pembuatan game ini Kami ingin memperkenalkan kembali tentang game arcade yang tidak hanya menghibur anak (just for fun) dari sisi permainan. (Rina Alfah, 2018) . Game ini yaitu diharapkan bisa menambah minat belajar untuk anak - anak sekolah dasar 
dengan menambahkan kegiatan bermain game yang bisa membuat mereka bermain sambil belajar tanpa terlalu membebani otak mereka dengan metode belajar konvensional.

\section{METODE PENELITIAN}

Desain untuk pengembangan yang digunakan dalam penelitian ini Yaitu Model ADDIE (Analysis-Design-DevelopmentImplementation-Evaluation). Tahapan desain pengembangan ADDIE yang kami gunakan dalam penelitian ini adalah sebagai berikut , ADDIE adalah Singkatan dari Analysis, Design, Development, Implementation dan Evaluation, dibawah merupakan rincian alur proses addie yang kami lakukan

1. Analisis : untuk analisis kebutuhan untuk menentukan masalah dan solusi yang tepat . masalah yang dihadapi mayoritas anak saat ini adalah kebiasaan bermain menggunakan smart phone/PC sangat tinggi. Solusi yang kami ingi terapkan agar anak bisa bermain smbil belajar yaitu dengan membuat Game Edukatif Bergenre Arcade khusus untuk anak sekolah dasar. Rancangan Metode / Model ADDIE Untuk Penelitian

2. Design : untuk Menentukan pendekatan pembelajaran, kemudian merancang design game edukatif bergernre Arcade yang biasa dimainkan oleh murid sekolah dasar tetapi dengan menyisipkan pertanyaan di beberapa Scene yang sesuai dengan mata pelajaran SD

3. Development : Mengembangkan design game edukatif tersebut dengan menggunakan Contruct 2

4. Implementation : Mengujicobakan Game yang sudah dibuat kepada Objek penelitian yaitu Anak/ Murid Sekolah Dasar

5. Evaluation : Melakukan analisis serta perbaikan jika terdapat kesalahan yang terjadi selama Proses penelitian

Game dengan genre Arcade sejak bertahun-tahun yang lalu seakan sudah menjadi ciri khas dari game mobile. Sudah banyak game jenis ini yang sukses. Misalnya saja sperti judul-judul seri Touhou, puzzle, N.O.V.A 3: Near Orbit Vanguar Alliance, Strike Wing : Rapto Rising, Demon Star, Astro Wings, dan sebagainya. Gameplay yang tidak serumit genre lainnya, genre ini dengan mudahnya banyak muncul di pasaran. Untuk itu kami menerapkan genre arcade untuk game yang kami rancang di karenakan lebih sederhana dan mudah untuk anak memainkannya dan anakanak tidak perlu skill atau kemahiran tingkat dewa untuk memainkannya. Kategori nya yaitu Auto Runner.

Sesuai dengan metode yang kami buat yaitu model ADDIE, yang pertama adalah membuat : Analisis. Untuk analisis kebutuhan yang menentukan masalah dan solusi yang tepat . masalah yang dihadapi mayoritas anak saat ini adalah kebiasaan bermain menggunakan smart phone/PC sangat tinggi. Solusi yang kami ingin terapkan agar anak bisa bermain smbil belajar yaitu dengan membuat Game Edukatif Bergenre Arcade khusus untuk anak sekolah dasar.

Selanjutanya adalah Rancangan Metode / Model ADDIE Untuk Penelitian ini yaitu membuat Design. untuk Menentukan pendekatan pembelajaran, kemudian merancang design game edukatif bergernre Arcade yang biasa dimainkan oleh murid sekolah dasar tetapi dengan menyisipkan pertanyaan di beberapa sesi game yang sesuai dengan mata pelajaran SD

Berikut FlowChart Sistem membangun Game Edukatif yang kami rancang :

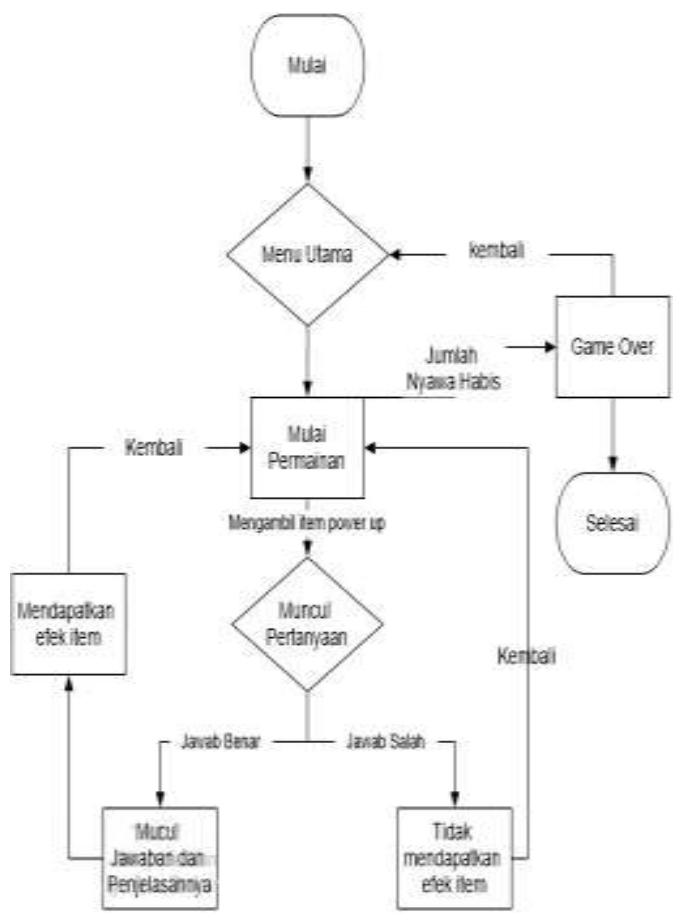

Gambar 1 Flowchart Sistem yang dibuat 
Algoritma yang digunakan untuk game arcade kategori Auto runner yaitu sebagai berikut :

1. Start

2. Mulai Permainan, player akan maju dengan sendirinya tanpa perlu kita tekan tombol. Saat player jalan akan ada rintangan berupa enemy/ musuh serta kaktus, jika tersentuh maka life/Kehidupan player akan berkurang, dan player nantinya juga dihadapkan dengan item point yang harus disentuh. Jika mengambil item point, maka akan lanjut ke langakah 3

3. Menampilkan Pertanyaan, jika menjawab benar maka akan lanjut ke langkah 4 dan jika salah menjawab akan kembali ke langkah 2

4. Memunculkan jawaban dan penjelasan dari pertanyaan ketika menekan tombol kembali akan kembali ke lagkah 2 dan mendapatkan efek dari item power up yaitu point .

5. Jika jumlah nyawa/life habis akan lanjut ke langkah 6

6. Memunculkan tampilan "GAME OVER", jika menekan tombol kembali akan kembali ke langkah 1

7. Finish

Berikutnya adalah rancangan activity diagram yang dibuat .

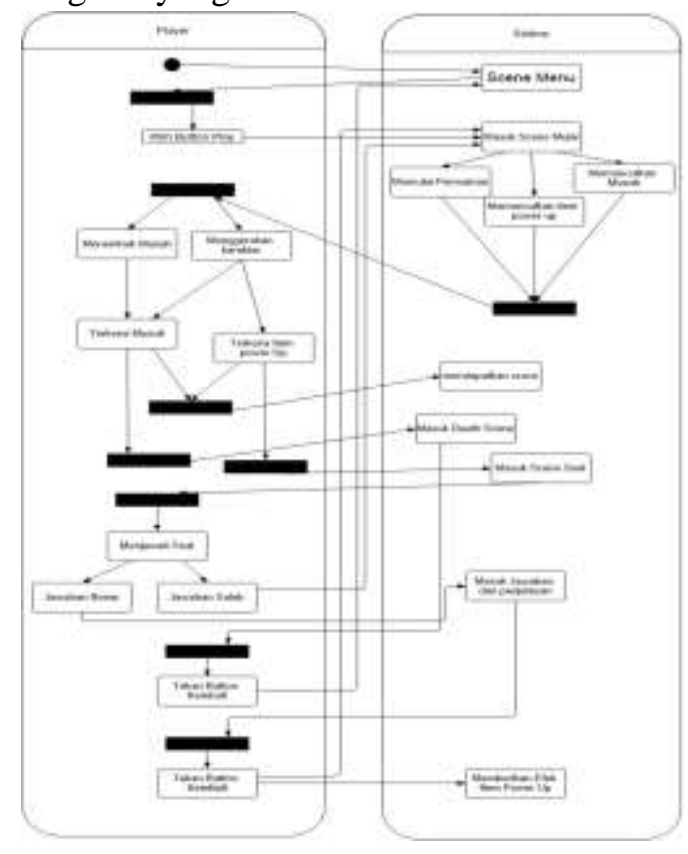

Gambar 2 Activity Diagram
Activity diagram menggambarkan untuk berbagai alir aktivitas dalam sistem yang dirancang yaitu bagaimana masing-masing alir berawal, decision/pilihan yang mungkin akan terjadi, dan bagaimana akan End/ berakhir. Activity diagram juga bisa menggambarkan beberapa proses parallel yang terjadi pada beberapa perilaku sistem yang dibuat .

Berikut juga kami cantumkan contoh rancangan design game sebelum kami buat/ melakukan Development . rancangan Design menggunakn Tools, Balsamiq Mockup.

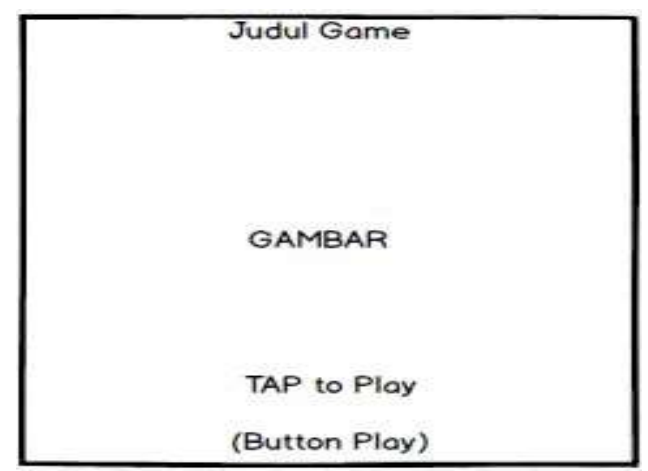

Gambar 3 Tampilan Screen menu Pembuka

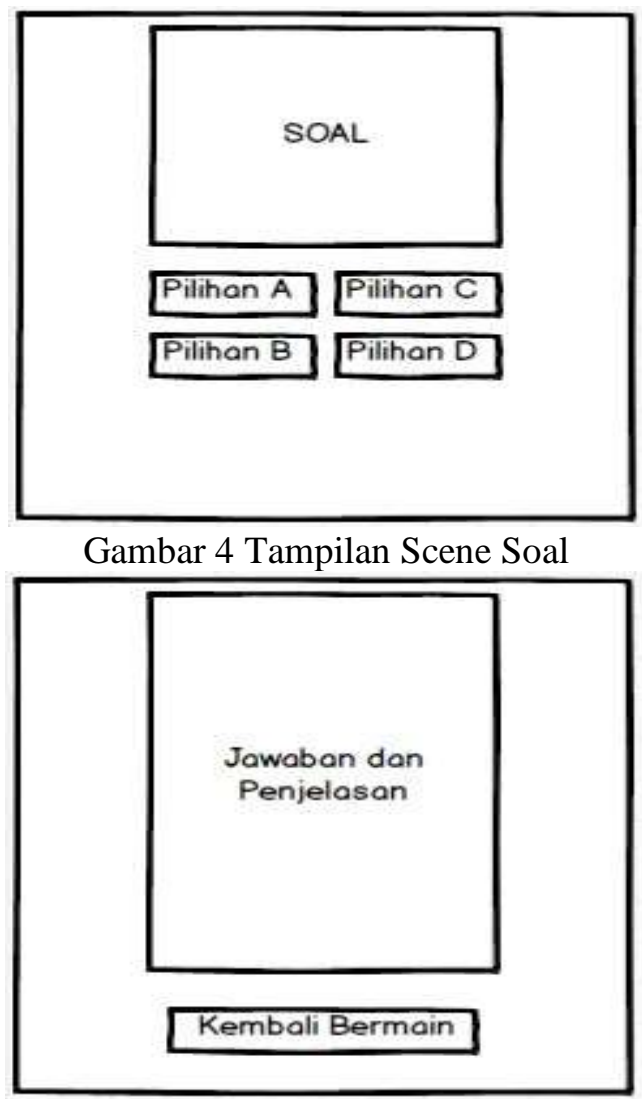

Gambar 5 Tampilan Scene Jawaban Soal 


\section{HASIL PENELITIAN}

Tahapan selanjutnya dalam Model ADDIE yaitu Development yaitu Mengembangkan design game edukatif tersebut dengan menggunakan Contruct 2 Berikut adalah Material yang digunakan dalam design game menggunakan Construct2. Pada Construct2 karakter utama adalah Player. Player yang dibuat berbentuk seorang anak laki-laki berseragam Sekolah Dasar bernama Boy. Selanjutnya adanya Musuh yang disebut Enemy. Disini karakter Enemy yang dipakai yaitu sosok - sosok monster lucu (karena memang game dirancang untuk anak-anak). Enemy nya ada tiga jenis (seperti terdapat pada gambar 6. Selanjutnya latar belakang game adalah background berwarna coklat dan hijau disebut Tile Background.

\section{Game Play Utama / Main Menu}

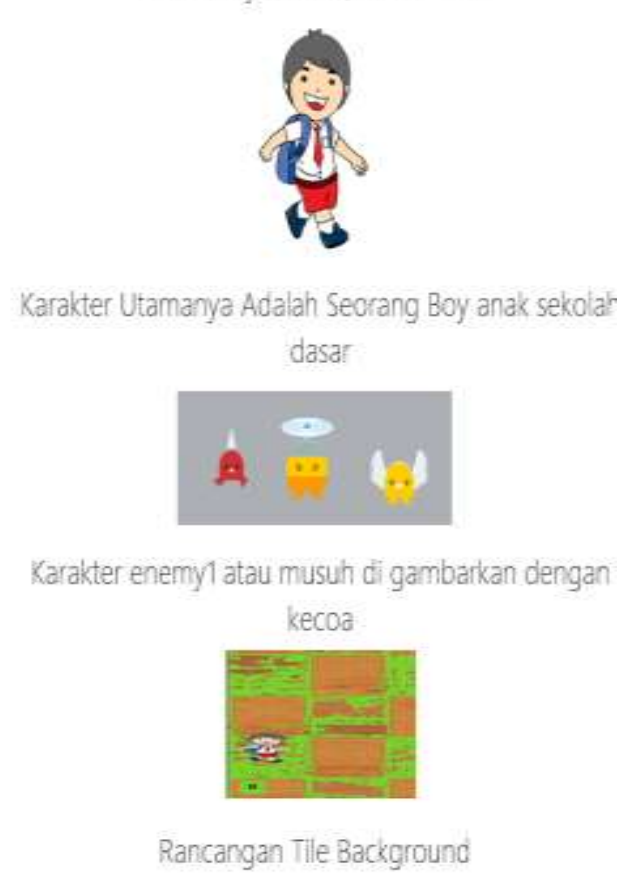

Gambar 6 Material Utama Game

Setiap perintah kerja pada pemrograman biasanya berbentuk coding, tetapi construct disebut dengan Even Sheet yang berisi perintah untuk gerakan dan efek karakter tertentu . Berikut adalah Contoh Evensheet yang dibuat pada game yang kami rancang .
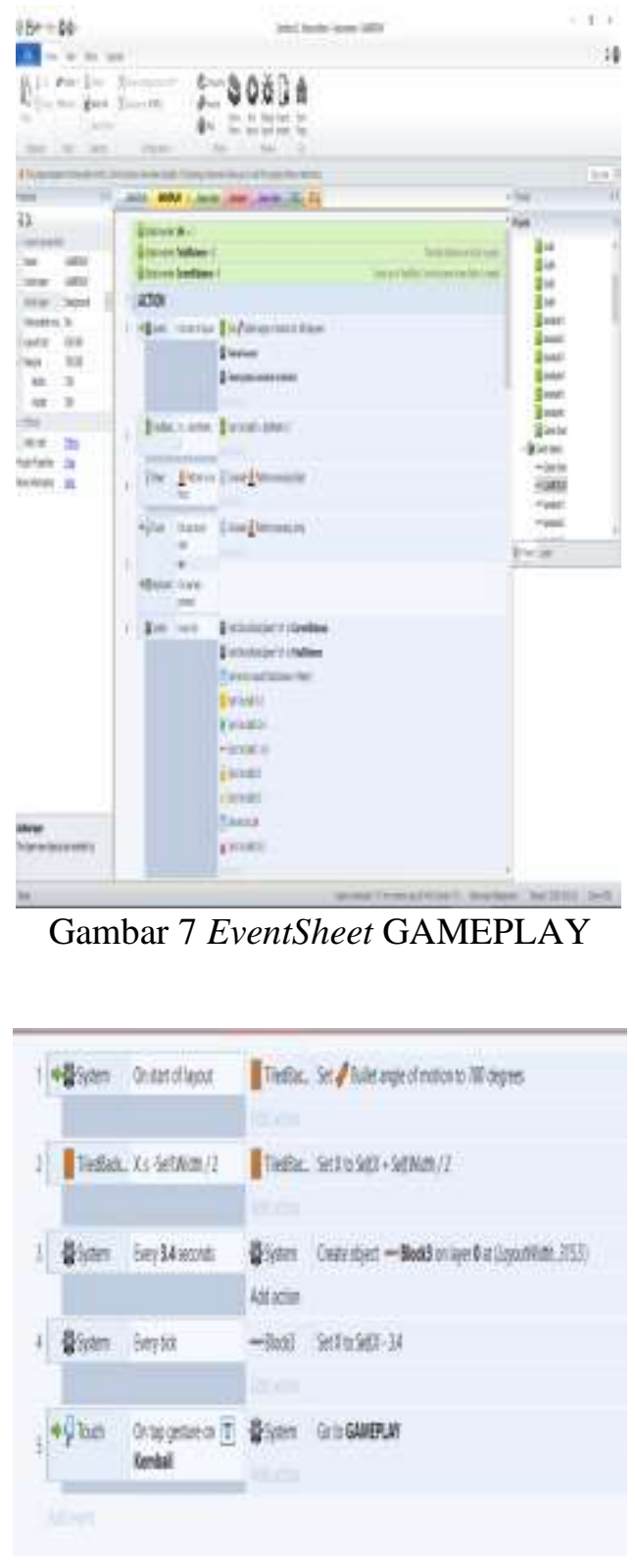

Gambar 8 EventSheet Jawaban

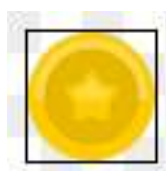

Gambar 9 Point yang akan memunculkan Soal

setiap kali player bertemu dan menyentuh Point, maka akan mucul scene yang berisi soal acak yang harus dijawab dengan pilihan ganda soal 


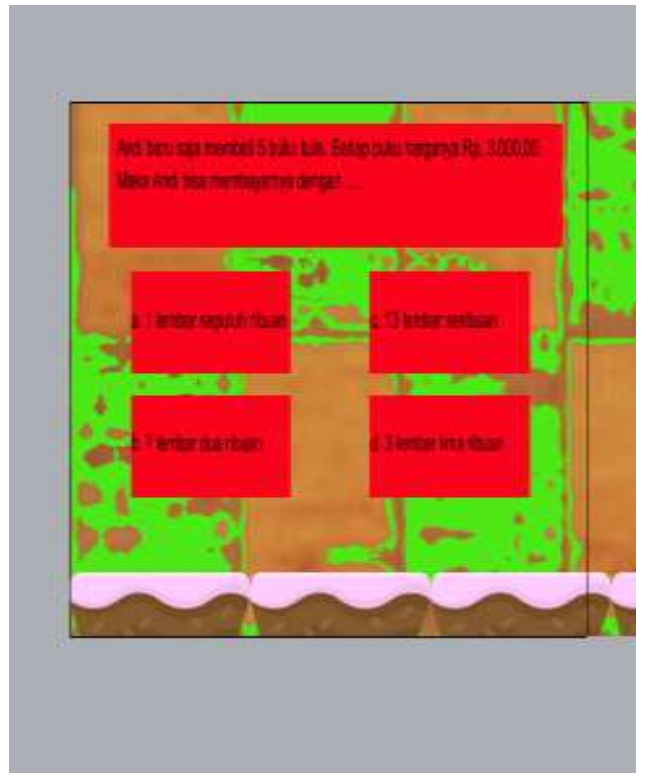

Gambar 10 Contoh Soal yang keluar

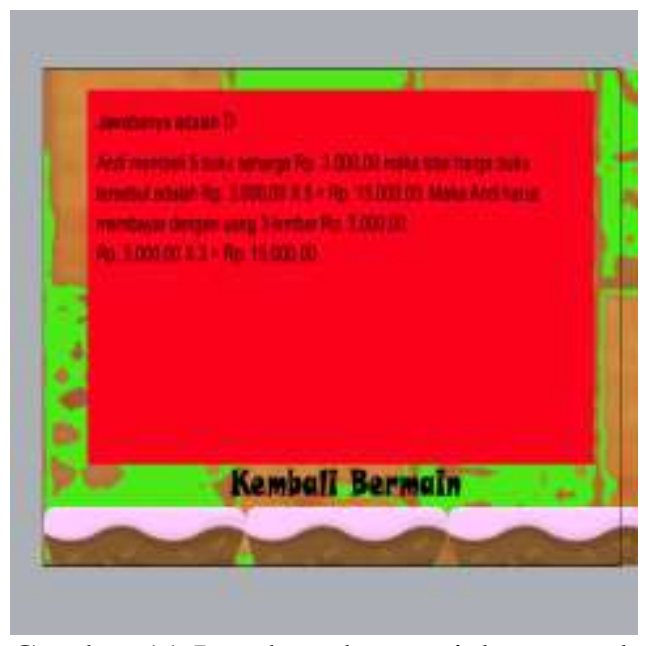

Gambar 11 Jawaban dan penjelasan soal

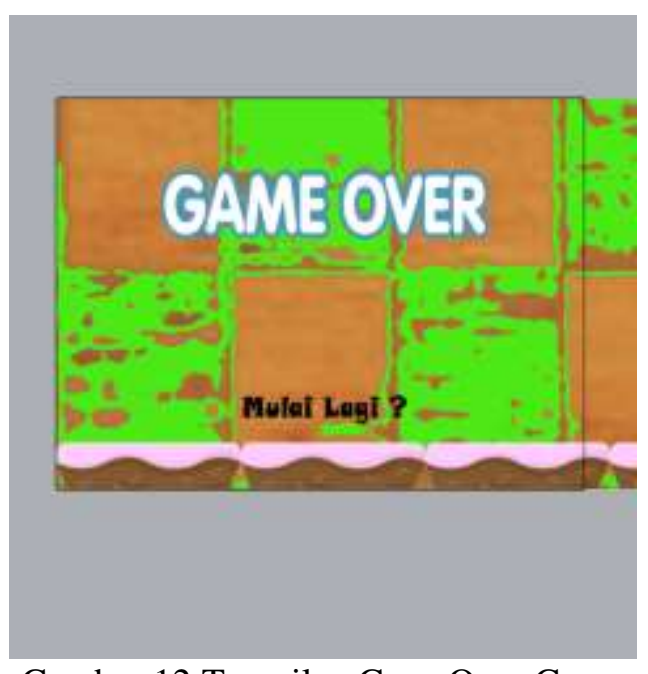

Gambar 12 Tampilan GameOver Game
Tahapan ADDIE berikutnya yaitu Implementation : yaitu Mengujicobakan Game yang sudah dibuat kepada Objek penelitian yaitu Anak/ Murid Sekolah Dasar. Kami mengumpulkan sample dengan memberikan game yang sudah kami buat kepada murid sekolah dasar kisaran umur 8 (delapan) tahun sampai dengan 12 (dua belas) tahun dalam waktu beberapa minggu. Selanjutnya kami melakukan tahapan selanjutnya yaitu Evaluation : yaitu Melakukan analisis serta perbaikan jika terdapat kesalahan yang terjadi selama Proses penelitian , Kemudian kami melakukan penilaian dengan menentukan score tertentu terhadap sample yang sudah kami dapatkan.

\section{KESIMPULAN}

Dari penelitian ini dapat disimpulkan bahwa Pembuatan game edukatif ini membuat anak-anak bisa bermain game tapi bukan hanya sekedar bermain saja tapi juga bisa belajar. Dengan adanya game ini menambah referensi hiburan mendidik untuk anakanak khususnya murid Sekolah Dasar selain itu Game ini bisa menjadi alternatif lain untuk bermain anak-anak dengan cara sederhana tapi tidak ketinggalan dalam teknologi yaitu perkembangan game secara mobile.

\section{REFERENSI}

[1] Alfah, R., 2016. Implementasi Peningkatan Citra X-Ray Menggunakan Komparasi Clip Limit Clahe Dengan Global Threshold Metode Graythresh. Technologia, 7(Vol 7, No 4 (2016)), pp. 21-27.

[2] Bhirawa, N. A. \& Sukardi, 2014. Pembuatan Website Portal Berita Desa Jetis Lor. IJNS-Indonesian 
Journal on Networking and Security.

[3] Damar, P. P., 2016. Bikin Game Tanpa Coding Dengan Construct 2. 1 penyunt. Yogyakarta: Andi Offset.

[4] Hutahaean, J., 2014. Konsep Sistem Informasi. Yogyakarta: CV. Budi Utama.

[5] Rina Alfah, T. V. R., 2018. Sistem E-Prescribing Dan BARCODE SYSTEM Untuk Resep Obat Di Rumah Sakit. Jurnal Teknologi Informasi Universitas Lambung Mangkurat (JTIULM), 03(Vol. 3 No. 2 (2018)), pp. 59-70.

[6] Roedavan, R., 2015. Construct 2 Tutorial Game Engine. Jakarta: Penerbit Informaatika.

[7] Safaat, N., 2014. Pemograman Aplikasi Mobile Smartphone dan Tablet. Bandung: Penerbit Informatika.

[8] Syamsu Rizal, E. R. A. I., 2013. Pengembangan Aplikasi Pencarian Lokasi Objek Wisata Terdekat Di Kabupaten Garut Berbasis Android. Sekolah Tinggi Teknologi Garut.

[9] Yuniar, S., 2014. Sетиa Bisa Menjadi Programmer Android. jakarta: Elex Media Komputindo. 